\title{
Development of the Latest High-performance Acid Copper Plating Additives for Via-Filling \& PTH
}

\author{
Shingo NISHIKI ${ }^{\dagger}$ \\ OKUNO CHEMICAL INDUSTRIES CO., LTD., Research, Metal Finishing, 1-10-25, Hanaten-higashi, \\ Tsurumi-ku, Osaka 538-0044 Japan
}

(Received December 10, 2012: Corrected December 14, 2012: Accepted December 14, 2012)

\begin{abstract}
Via-filling plating and through-hole plating are absolutely imperative for manufacturing of printed-wiring board. This Paper is introducing the latest developments of our company worked on the high-performance of acid copper plating additives for them.
\end{abstract}

Keywords: Acid Copper Plating Additives, Via-Filling Plating, Through-Hole Plating, Leveler, Productivity Improvement

\section{Introduction}

Through-hole and via-filling plating are important and necessary process for manufacturing of printed-wiring board and the technologies applied to various fields. We have started developing acid copper plating additives for printedwiring board early and launched many products into the market. Recently, demand of cost reduction for printedwiring board becomes strong due to intensified competition among companies and improvement of productivity is also required on plating process. In electroplating, shortening plating process by increased current density is the most effective method for improving productivity and developing acid copper plating additives applicable to this condition is required

On this report, I would introduce our latest and next generation type acid copper plating additives in order to meet the demand of productivity improvement.

\section{Contribution of Additives in Acid Copper Plating}

\subsection{Via-Filling Plating}

Deposition mechanism of via-filling plating can be explained by the interaction of two leveling known as memory theory ${ }^{1)}$ and diffusion theory. The scheme of each theory is shown on figure 1.

\subsubsection{Memory Theory}

Absorption of brightener as DCA (Depolarizing Control Agent) has an ability to provide smoothness (leveling) on the film. DCA is absorbed uniform, regardless of area, on
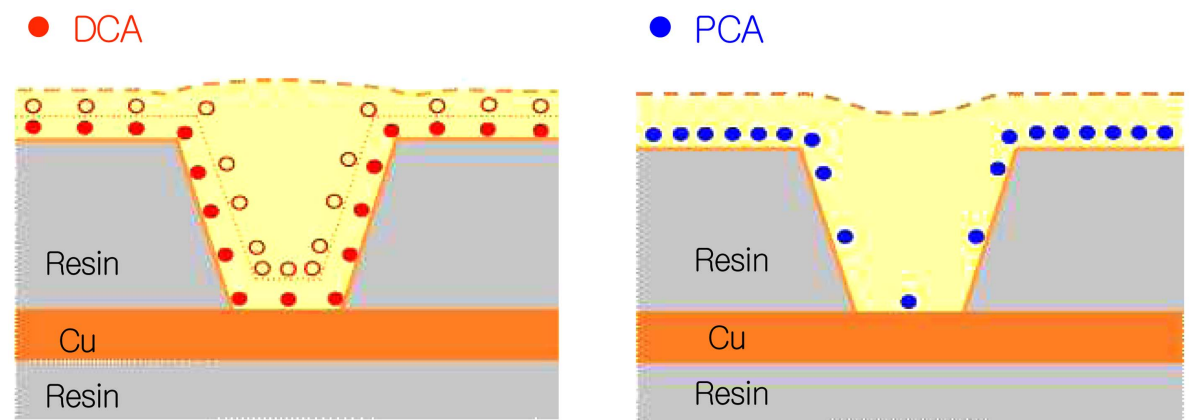

Fig. 1. deposition mechanism for via-filling.

\footnotetext{
${ }^{\dagger}$ Corresponding author

E-mail: s-nishiki01@okuno.co.jp

(C) 2012, The Korean Microelectronics and Packaging Society

This is an Open-Access article distributed under the terms of the Creative Commons Attribution Non-Commercial License(http://creativecommons.org/ licenses/by-nc/3.0) which permits unrestricted non-commercial use, distribution, and reproduction in any medium, provided the original work is properly cited.
} 
flat and concavity, however, absorption becomes dense at the concavity area where the surface area is small with growth of plating. Hence, it promotes reaction of electrodeposition at the concavity area and it is considered that smoothness on plating film is provided.

\subsubsection{Diffusion Theory}

Absorption of brightener as PCA (Polarizing Control Agent) has an ability to provide smoothness (leveling). PCA is under diffusion control and a large amount of PCA is absorbed at flat area where diffusion layer is thin, on the other hand, a small amount of PCA is absorbed at concavity area where diffusion layer is thick. Diffusion layer is a thin layer near electrode and the layer having low concentration of reactant by electrode reaction. As a result, electro-deposition reaction at flat area is inhibited and it is considered that smoothness is provided on plating film by plating deposit on concavity area preferentially.

\subsection{Through-hole Plating}

Throwing power is generally shown as calculation (1). Throwing power is decided by the product of conductivity and polarization dimension at cathode. Therefore, the higher the bath conductivity is and the bigger the polarization dimension at cathode is, the more throwing power improves.

$$
\text { Parameter of Throwing Power }=\frac{\Delta \eta / \Delta i}{\rho}
$$

$\rho=$ Resistivity of plating solution

$\Delta \eta=$ Change of over potential at cathode

$\Delta i=$ Change of current density

\section{$\Delta \eta / \Delta i=$ Polarization dimension of plating solution}

Consequently, throwing power of acid copper plating solution is decided by concentration of sulfuric acid which controls conductivity and inhibitor of electro-deposition (polymer and leveler) which relates to polarization dimension at cathode. Selection of polymer and leveler as inhibitor of electro-deposition is important in order to improve throwing power of acid copper plating. Especially, leveler influence throwing power significantly.

\section{Influence of Increase Current Density in Conventional Bath}

\subsection{Influence of Current Density Increase on Performance} of Through-hole and Via-filling Plating in Conventional Bath

The plating condition of via-filling performance and through-hole corner at current density $1.0 \mathrm{~A} / \mathrm{dm}^{2}$ and $2.0 \mathrm{~A} /$ $\mathrm{dm}^{2}$ with conventional product is shown figure 2 . It shows that excellent filling performance at current density $1.0 \mathrm{~A} / \mathrm{dm}^{2}$ and any plating problems at through-hole corner is not found. However, performance of via-filling and thickness at through-hole corner decline is found when current density increases to $2.0 \mathrm{~A} / \mathrm{dm}^{2}$. Therefore, performance degradation is caused by increase of current density above $1.0 \mathrm{~A} / \mathrm{dm}^{2}$ which is standard condition.

\subsection{Factor of Performance Decline by Current Density}

\section{Increase}

As mentioned above, absorption of leveler as inhibitor of electro-deposition is under diffusion control and a large amount of leveler is absorbed at thin diffusion layer where

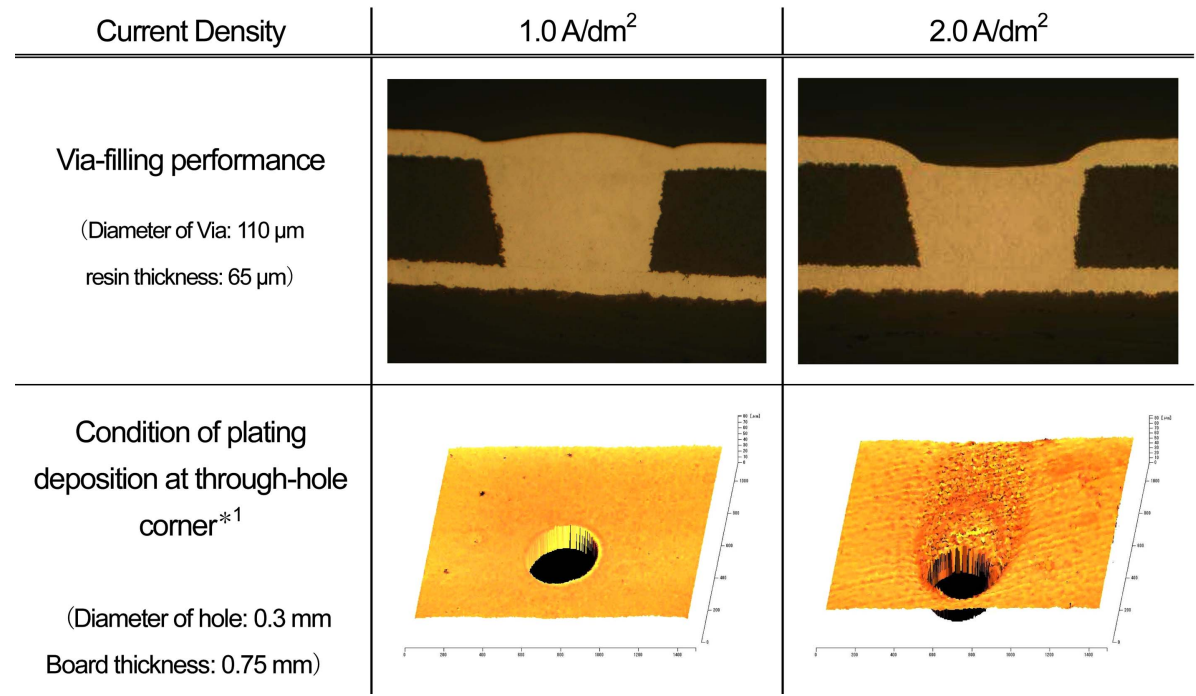

Fig. 2. Influence of Current Density Increase on Through-hole and Via-filling Plating in Conventional Bath. *1 Image by Laser Microscope (Keyence Corp. : VK-8500) 


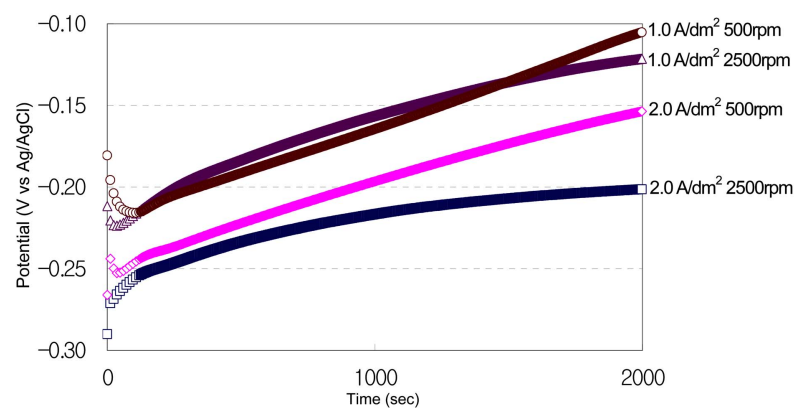

Fig. 3. Cathodic Potential Change at Constant Current Electrolysis in Conventional Bath (iusing SLQ-250 made by Toppan Printing Co., Ltd.)

the agitation is strong, on the other hand, a small amount of leveler is absorbed at thick diffusion layer where agitation is weak.

Polarization dimension at cathode is measured at the condition of constant current electrolysis in conventional bath in order to analyze how diffusion control of leveler with current density increase in conventional bath affects. Potential was measured under the condition as rotation frequency of platinum electrode $2500 \mathrm{rpm}$ and $500 \mathrm{rpm}$. The result is shown on figure 3 .

According to the figure 3 , potential changes to the noble side according to proceeding of the time on both $2500 \mathrm{rpm}$ and $500 \mathrm{rpm}$. Variation is getting small gradually at $2500 \mathrm{rpm}$, on the other hand, it continues to change at $500 \mathrm{rpm}$ and potential difference between $2500 \mathrm{rpm}$ and $500 \mathrm{rpm}$ occurs after 2400 seconds. Potential difference by agitation is small at current density $1.0 \mathrm{~A} / \mathrm{dm}^{2}$, but it becomes large at current density $2.0 \mathrm{~A} / \mathrm{dm}^{2}$. It is caused by current density increase and it is considered that adsorption of leveler becomes under diffusion control. It is shows the factor of film thickness decline at through-hole corner where the agitation is strong.

\section{Importance of Leveler for Via-filling and Through-hole Plating}

As mentioned above, leveler has an important role for via-

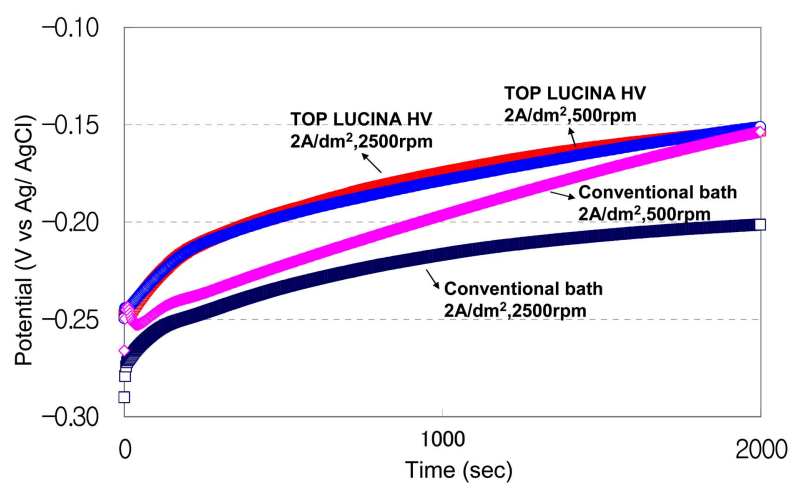

Fig. 4. Result of Cathodic Potential Measurement of TOP LUCINA HV by Constant Current Electrolysis (iusing SLQ-250 made by Toppan Printing Co., Ltd.)

filling and through-hole plating. We has optimized leveler and developed two next generation acid copper plating additives "TOP LUCINA HT" and "TOP LUCINA HV" in order to improve productivity by high concentration. TOP LUCINA HV improve film thickness decline at through-hole corner with current density increase which had been a problem in conventional bath. TOP LUCINA HT achieved high throwing power by high polarization dimension at cathode.

\section{TOP LUCINA HV}

\subsection{Development of TOP LUCINA HV}

For development of TOP LUCINA HV, we made leveler concentration high and searched leveler component which does not spoil effect of brightener. In that case, cathodic potential change measurement by constant current electrolysis shown special behavior of additive was used for evaluation. As a result, we found leveler component without influence of rotation frequency of rotation electrode for cathodic potential change shown figure 4 and showed nobler potential than conventional bath. It is not likely to cause difference of plating film thickness by strength of agitation and it does not spoil effect of brightener. It is expected to improve film thickness decline at through-hole corner and degradation of via-filling performance recognized with

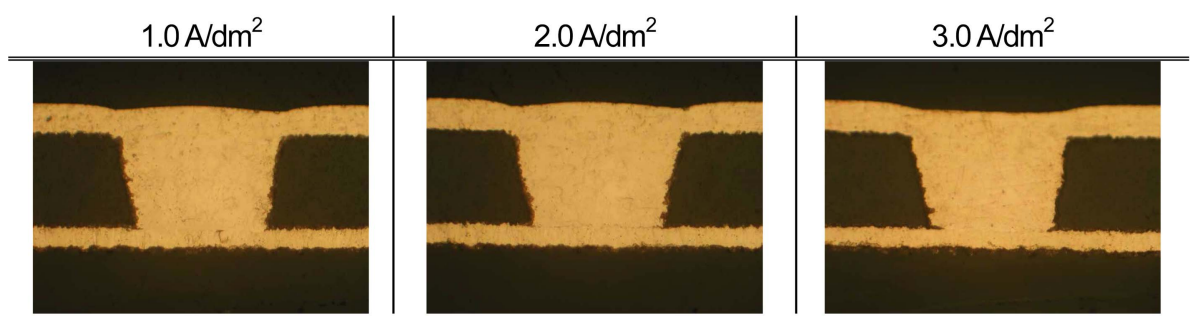

Fig. 5. Via-filling Performance of TOP LUCINA HV (Diameter of Via: $110 \mu \mathrm{m}$, resin thickness: $65 \mu \mathrm{m}$ ) 


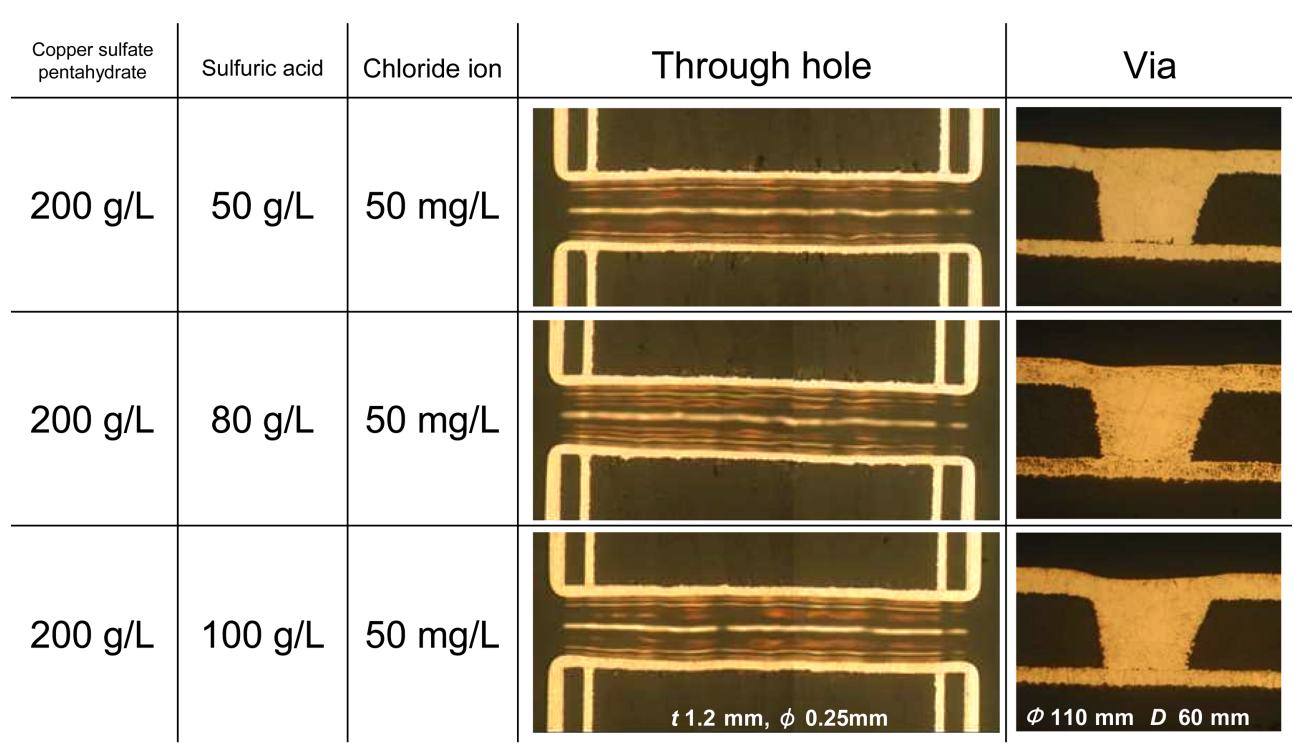

Fig. 6. Through-hole Plating Performance of TOP LUCINA HV.

conventional. This leveler component is used for TOP LUCINA HV.

\subsection{Performance of TOP LUCINA HV}

Via-filling plating performance of TOP LUCINA HV is shown as figure 5 and plating performance for through-hole is shown as figure 6 .

According figure 5, TOP LUCINA HV provides excellent via-filling performance for wide range of current density and can be also applied at $3.0 \mathrm{~A} / \mathrm{dm}^{2}$. According to figure 6 , it shows excellent through-hole plating maintaining viafilling performance for board with high aspect. It also increases the concentration of sulfuric acid and film thickness inside of hole.

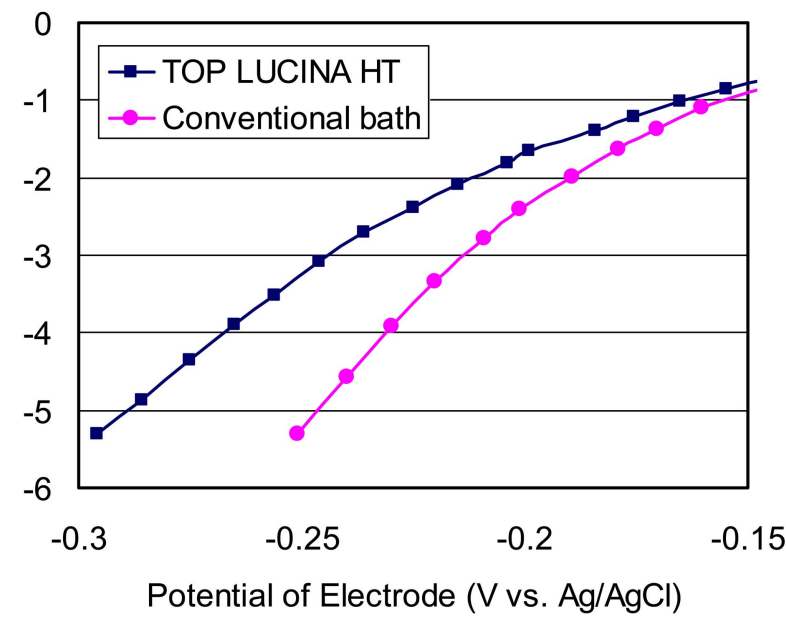

Fig. 7. Cathode Polarization Curve of TOP LUCINA HT and Conventional Bath.

\section{TOP LUCINA HT}

\subsection{Polarization of Cathode}

We had developed leveler having a large polarization based on formula (1). As a result, we found leveler which has a large polarization and does not hinder effect of brightener when it is high concentration. Polarization curve of cathode is shown as figure 7 comparing with conventional bath. It was measured by scanning potential method using three-electrode method cell. Vicinity of current density used for actual plating is shown as enlarged view.

It shows that the slope of TOP LUCINA HT is gentler than conventional product and it has high throwing power.

\subsection{Performance of TOP LUCINA HT}

The result of throwing power measurement with current

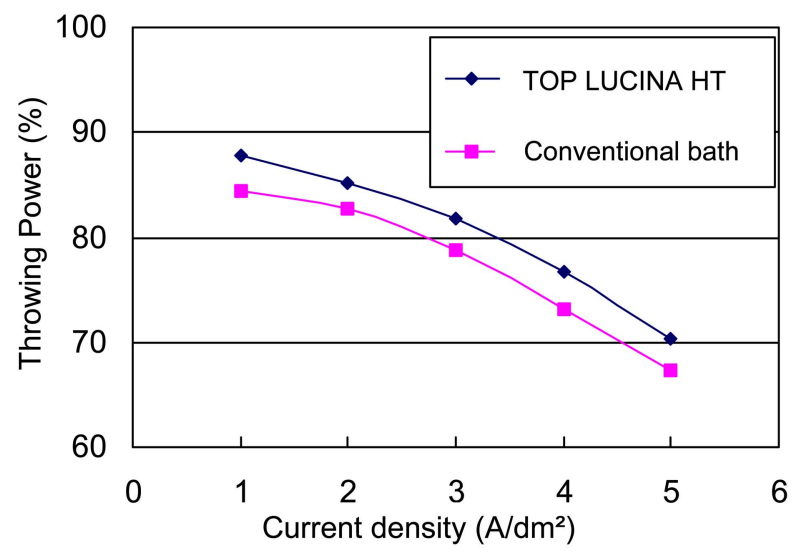

Fig. 8. Throwing Power Comparison of TOP LUCINA HT and Conventional Bath. (Board thickness: $1.6 \mathrm{~mm}$, Hole diameter: $0.3 \mathrm{~mm})$ 


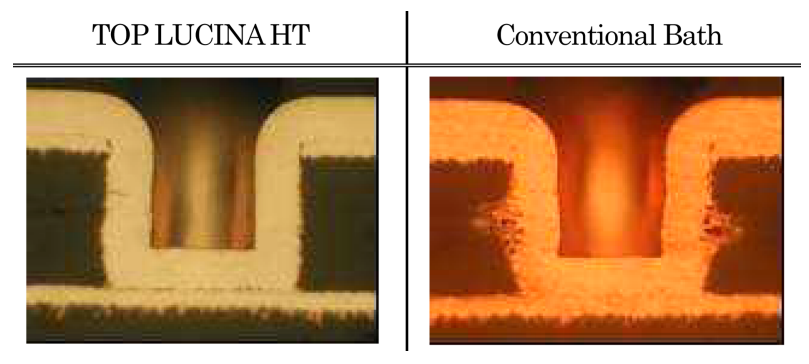

Fig. 9. Covering Power Comparison of TOP LUCINA HT and Conventional Bath for BVH Current Density $=3 \mathrm{~A} / \mathrm{dm}^{2}$ Diameter of via: $0.13 \mathrm{~mm}$ Board thicknes: $1.0 \mathrm{~mm} \mathrm{CuSO}_{4} \cdot \mathrm{E}^{2} \mathrm{H}_{2} \mathrm{O}: 100 \mathrm{~g} /$ $\mathrm{L}, \mathrm{H}_{2} \mathrm{SO}_{4}: 180 \mathrm{~g} / \mathrm{L}, \mathrm{Cl}^{-}: 50 \mathrm{mg} / \mathrm{L}$.

density change of TOP LUCINA HT and conventional bath is shown as figure 8 and figure 9 shows covering power of plating for BVH. According to figure 8, TOP LUCINA HT provides higher throwing power at wide range of current density than conventional bath. As shown on figure 9, TOP
LUCINA HT has same covering power as conventional product and provides excellent performance for not only through-hole but BVH mixed board.

\section{Conclusion}

We have focused on leveler of acid copper plating additive and developed acid copper plating additive for printed wiring board having high performance as "TOP LUCINA HV" and "TOP LUCINA HT" in order to be applied to via-filling and through-hole plating at high current density. We expect that both products will contribute to improve productivity of printed wiring board manufacturing.

\section{References}

1. O. Kardos, "Current Distribution on Microprofiles Part III", Plating, 61(4), 316 (1974). 